\title{
Rhinoplasty: \\ A Multispecialty Approach
}

Editor

BABAK AZIZZADEH

\section{CLINICS IN \\ PLASTIC SURGERY}

www.plasticsurgery.theclinics.com

Section Editors

DANIEL BECKER

RONALD P. GRUBER

January 2016 • Volume 43 - Number 1 